\title{
NOTES ON TINGIDA.
}

\section{By Herbert Osborn and Carl J. Drake.}

In recent numbers of Psxche, ${ }^{1}$ Mr. H. M. Parshley has presented articles on Tingidæ in which he has called attention to what he considers errors in articles written by the writers and offered numerous criticisms that it seems necessary to note. In so far as these criticisms and corrections are warranted they are of course to be welcomed, but there are many instances in which a careful reëxamination of material studied and a study of material coming to hand since our papers were published fail to establish the validity of Mr. Parshley's criticisms. Some of these are considered in the following notes and others are discussed in a paper in the Ohio Journal of Science. (Vol. XVII, pp. 295-307.)

Fenestrella ovata Osborn \& Drake (Plate VIII, Fig. $d$ ).

The criticism by Parshley of the drawing of this species in his second paper is quite inaccurate as a comparison of the photograph (Fig. $d$ ) of the type with the drawing will indicate. The statement, "the base of the third antennal segment is slightly capitate," is entirely absurd as there is no such structure present, and, furthermore, capitate refers to a structure at the distal end of a segment. We have recently received a second specimen of this unique little form from Ohio.

Key to the Nearctic Species of Physatocheila.

1-Rostrum short, reaching between the intermediate coxæ

P. brevirostris Osb. \& Drk.

Rostrum considerably longer and of various lengths.......2 2-Rather large insects (length $4.6 \mathrm{~mm}$.), second antennal segment small at the base and much enlarged at the apex.

P. major n. sp.

Smaller insects (length $4 \mathrm{~mm}$. or less), second antennal segment not as the above. . . . . . . . . . . . . . . . 3

3-Rostrum not extending beyond the apex of the rostral sulcus; outer costate nervure that bounds discoidal area nearly straight; color dull, uniform yellowish-brown.

P. parshleyi n. n. (= plexa Parsh.)

1 December, 1916; February, 1917. 
Rostrum reaching more or less beyond the rostral sulcus; outer costate nervure that bounds discoidal area sinuate; color either brownish, or brownish more or less tinged with yellow, or brown or grayish brown variegated with pale cinereous and black, or cinereous.

$$
\text { P. plexa Say (= P.variegata Parsh.) }
$$

Physatocheila parshleyi nom. nov. (= P. plexa Parsh.).

This species was described by Parshley in his first paper as the true form of $P$. plexa Say. Although the species meets the requirement of the writer's contracted form of Say's description and his assumed characters of a true plexa it is distinctly at variance with the original description if taken in its entirety. Compare as follows: (Say) "Body brownish, more or less tinged with yellow" surely cannot be the same as (Parshley) "Uniform dull yellowish brown"; (Say) "two series of which on the lateral margins are a little larger," in reference to the reticulations of the elytra is hardly identical with (Parshley) "Costal area of the hemielytra with two almost regular series of areoles"; the rostrum is not mentioned in the original description of plexa and the length of the rostrum is entirely an assumed character by Parshley. It might be well to note that the length of the rostrum is not given by Say in any Tingid description, also that this species has never been taken in the regions where Say did his entomological work. In as far as we know this species has only been taken in the New England States and eastern Canada; plexa is a common species in the states where Say worked and our collections include numerous specimens of this species from Portland, Oregon, to the Atlantic Ocean. The structures mentioned in the key will readily separate this species from allied forms and the other characters can be noted in Parshley's first paper under plexa Say.

Physatocheila plexa Say, Uhler, Heidemann, Osborn \& Drake (=variegata Parshley, but not plexa).

The conclusions drawn by Parshley in his first paper are based on a special interpretation of Say's description and a few assumed characters as indicated below. 
Parshley.

". . . brownish, more or less tinged with yellow," and ". . . two series [of reticulations] . . on the lateral margins . . [of the hemielytra] . . . ."
SAY.

"Body brownish, more or less tinged with yellow, with dilated approximate punctures; head with three elevated lines: thorax not dilated on the sides; with three elevated lines: scutel also with three elevated lines: hemielytra with small, symmetrical, orbicular reticulations of nervures; two series of which on the lateral margins are a little larger; those near the inner margin of the membrane also a little larger."

The color description of plexa is rather indefinite as only the color of the body is mentioned by Say and this is not of a constant and uniform color as distinctly indicated by the words, "more or less tinged with yellow." By omitting "of which" Parshley gives a different meaning to the portion of the description which describes the lateral margins of the elytra; and, furthermore, in the form that the author calls variegata (= plexa Say) the costal area is not always either triseriate or averaging three rows of areolæ as stated in the description. Evidently, the writer failed to study all his paratypes as Fig. $1, b$ will indicate; this is a photo-

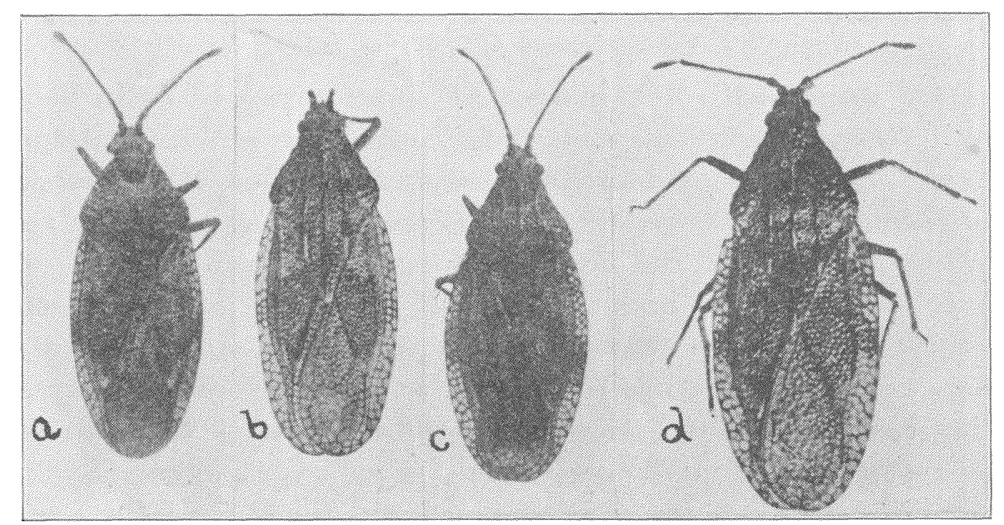

Fig. 1. $a, b$, and $c$, Physatocheila plexa Say (=variegata Parsh.): $d, \mathbf{P}$. major. n. s. p. (Photographs by Carl J. Drake.) 
graph of the paratype from Wellesley, Mass., which was sent to the junior author by Parshley as a typical form of variegata. As stated under parshleyi, Say never mentioned the length of the rostrum in any Tingid, and the length there given is only an assumed character.

Our collections include specimens from Oregon (Portland), Idaho, Nebraska, Kansas, Iowa, Wisconsin, Illinois, Michigan, Virginia, New York, and Massachusetts. Stål also records the species from "Illinois." This series of specimens indicate the species to be quite variable, especially in color, length of rostrum, and in number of rows of areolæ in costal area, but there seems to be no distinct variety. The many variations in color may be noted in the key. Our Illinois specimens are almost of a uniform brownish color and the costal area is quite uniformly biseriate. The costal area of the elytra is either uniformly biseriate, or triseriate, or more or less irregularly triseriate, or with various intermediate forms between bi- and triseriate. The length of the rostrum is quite variable, always extending beyond the end of the rostral sulcus, but never reaching beyond the posterior margin of the second abdominal segment. In taking the length of the rostrum one should always note the position of the head and prothorax. In the senior author's collections are specimens determined by Uhler and Heidemann. The specimen determined by Heidemann is listed by Parshley as a paratype under variegata from Berkeley Springs, Va.

\section{Physatocheila major sp. nov.}

Head armed with five spines, the spines arranged as in plexa Say. Antenniferous tubercules large, curved inwardly. Antennæ clothed with fine short hairs; basal segment swollen, a little longer than the second; second segment short, small at the base and strongly swollen at the tip; third segment longest, slenderest, about two and a half times the length of the fourth; fourth segment fusiform. Pronotum tricarinate, the carinæ low and uniseriate; lateral margins as in related species; hood a little larger than in other Nearctic species. Rostral sulcus broad, the rostrum almost reaching posterior margin of second abdominal segment. Elytra a little longer than the abdomen, broadly rounded at the apex; costal area rather broad, irregularly areolate, with two or three confused rows of areolæ; discoidal area a little broader and the 
outer boundary slightly more sinuate than in plexa. Wings slightly longer than abdomen. Abdomen quite broad in both male and female. Length, $4.6 \mathrm{~mm}$.; width, $1.8 \mathrm{~mm}$.

Color.-General color brownish, slightly marked with yellowish and black. Antennæ brownish, the distal half of apical segment blackish.

Two specimens, a male and female from Urbana, Illinois. The photograph illustrates the type specimen; all specimens of Physatocheila are equally enlarged. This species is readily separated from allied forms by its larger size and the second segment of the antennæ.

Melanorhopola duryi Osborn \& Drake (Plate VIII, Fig. e).

The form of this species is not very broad when compared with females of other species in the genus. The third antennal segment is slightly enlarged towards the apex and the distal segment is decidedly conical rather than fusiform as stated by Parshley in his second paper. The photograph of the type will illustrate the structures mentioned. All photographs of the species in this genus are of the same magnification and the antennæ have been placed in a horizontal position with the body so that the proportions between the same or different species are quite accurate.

Melanorhopola clavata Stål (Plate VIII, Figs. $a, b$ and $c$ ).

This is a common and well-known species in the

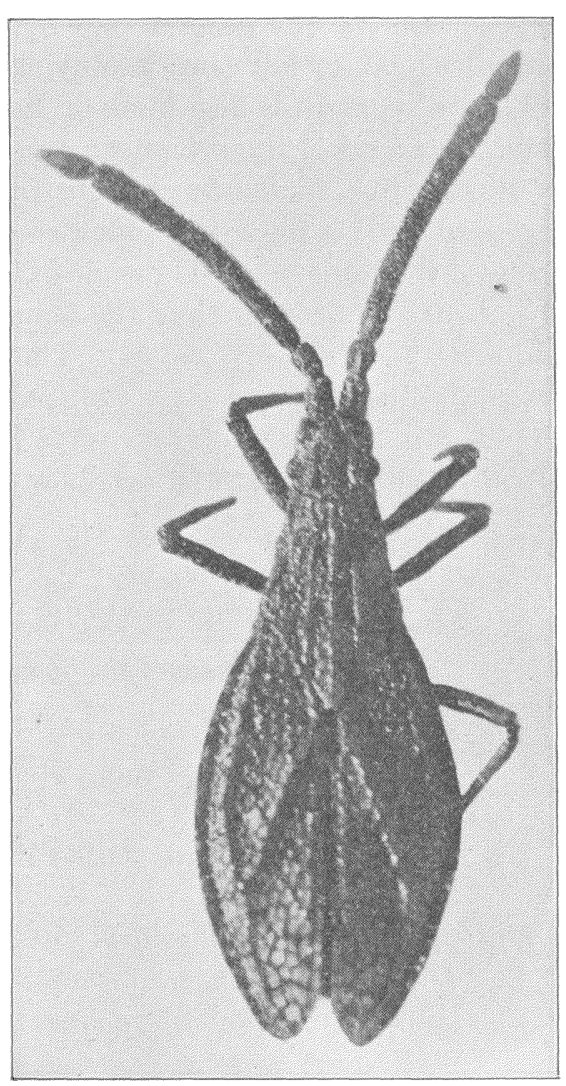

Fig. 2. Melanorhopola duryi sp. nov., much enlarged. (Photo by Drake.) 
eastern part of United States. Our most western records are Iowa and Nebraska. The photographs show the difference between the short winged and long winged forms, also the extreme variations in the lengths of the antennæ.

\section{Melanorhopola uniformis Stål (Plate VIII, Fig. $f$ ).}

This species, as we determined it, is quite closely allied to lurida. The photograph represents the South Dakota specimen listed in our Ohio bulletin.

Melanorhophola lurida Stål (Plate VIII, Figs. $h$ and $g$ ).

Parshley has erroneously stated the length of the antennæ of this species in his second paper. The antennæ either slightly exceed, equal, or fall considerably short of the tip of the abdomen; the third segment is also more or less swollen near the apex. The lateral margins of the pronotum are either vertical or reflexed more or less against the surface of the pronotum. The form of lurida and uniformis is also very much confused and not based on specimens of the same sex. The male of lurida is narrow, but the female is as broad or broader than the female of uniformis. The male of uniformis is unknown to us. The Figures $f$ (uniformis) and $g$ (lurida) illustrate the short winged females of the two species; Figure $h$ is the macropterous male of lurida. The two specimens of lurida show almost the extreme variations in the length of the

\section{Explanation of Plate.}

Photographs by Carl J. Drake.

Figs. $a, b$, and $c$. Melanorophola clavata Stål ( $a$, macropterous female; $b$ and $c$, brachypterous females, the latter with short antennæ).

Fig. $d$. Fenestrella ovata Osborn and Drake (type greatly enlarged).

Fig. e. Melanorophola duryi Osborn and Drake (type).

Fig. $f$. Melanorophola uniformis Stål (brachypterous female).

Figs. $g$ and $h$. Melanorophola lurida Stål ( $g$, brachypterous female with short antennæ; $h$. macropterous male with long antennæ). 
antennæ in this species. The size of lurida in our series of twentyfour specimens varies in length from $4.35 \mathrm{~mm}$. to $5.8 \mathrm{~mm}$. It is impossible to separate the smaller specimens of lurida from $o b$ scura Parsh., by the inadequate and obscure description nor by the characters used in the key to the genus in his second paper. In both of these papers a great deal of emphasis is placed on size, narrow form, and antennal structures that apply equally well to the smaller specimens of lurida. Possibly an examination of the types may enable one to separate them.

\section{BOOK REVIEWS.}

The Mosquitoes of North and Central America and the West Indies. By L. O. Howard, H. G. Dyar and Frederick Knab.

Volume 1, pp. I-VI, 1-520, 1912.

Volume 2, pp. I-X, Plates 1-150, 1912.

Volume 3, pp. I-VI, 1-523, 1915.

Volume 4, pp. 525-1064, 1917.

A notable chapter in that branch of Dipterology known as Culicology has been completed by the appearance of Volume 4 of this magnificent contribution to the knowledge of American mosquitoes-a work which reflects high credit not only upon the authors and the institution which made publication possible, but also upon the recognition entomology has won and which really has made possible the completion of such a comprehensive and exhaustive study. It is a response to the recognition of the vital relation certain species of mosquitoes sustain to the welfare of the human race, and a demonstration of the fact that the knowledge of pathogenic forms is incomplete without a study of associated and allied species.

The older entomologists easily recall the earlier days when only a few supposedly uninteresting and assumedly similar or very similar species of mosquitoes were known to occur in America, and can compare the conditions then and those obtaining now with practically 400 recognized species referable to 25 genera, and presenting undreamed of biological and morphological diversities,- 
Psyche, 1917.

Vol. XXIV, Plate X.

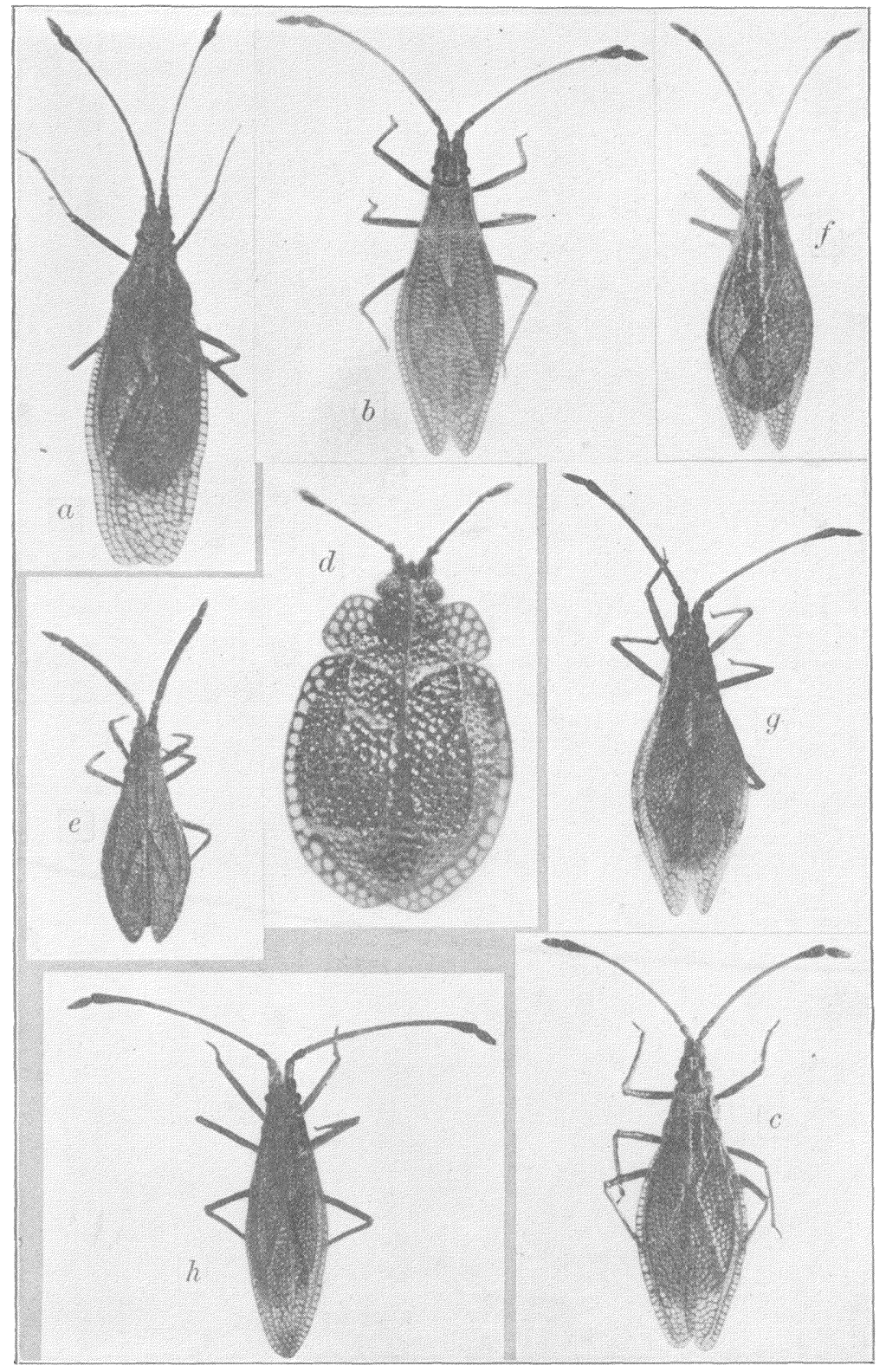

Osborn and Drake-Tingidor. 

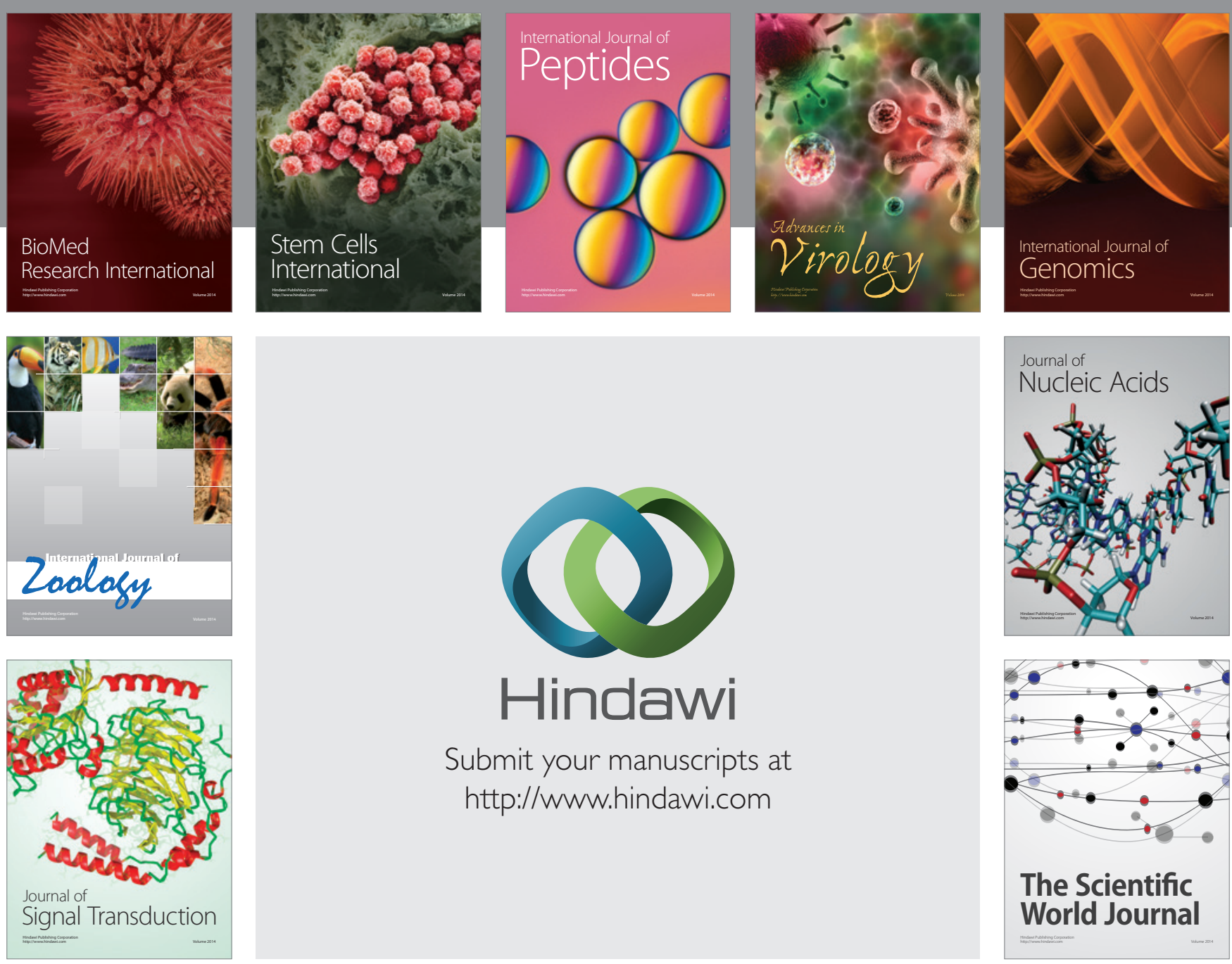

Submit your manuscripts at

http://www.hindawi.com
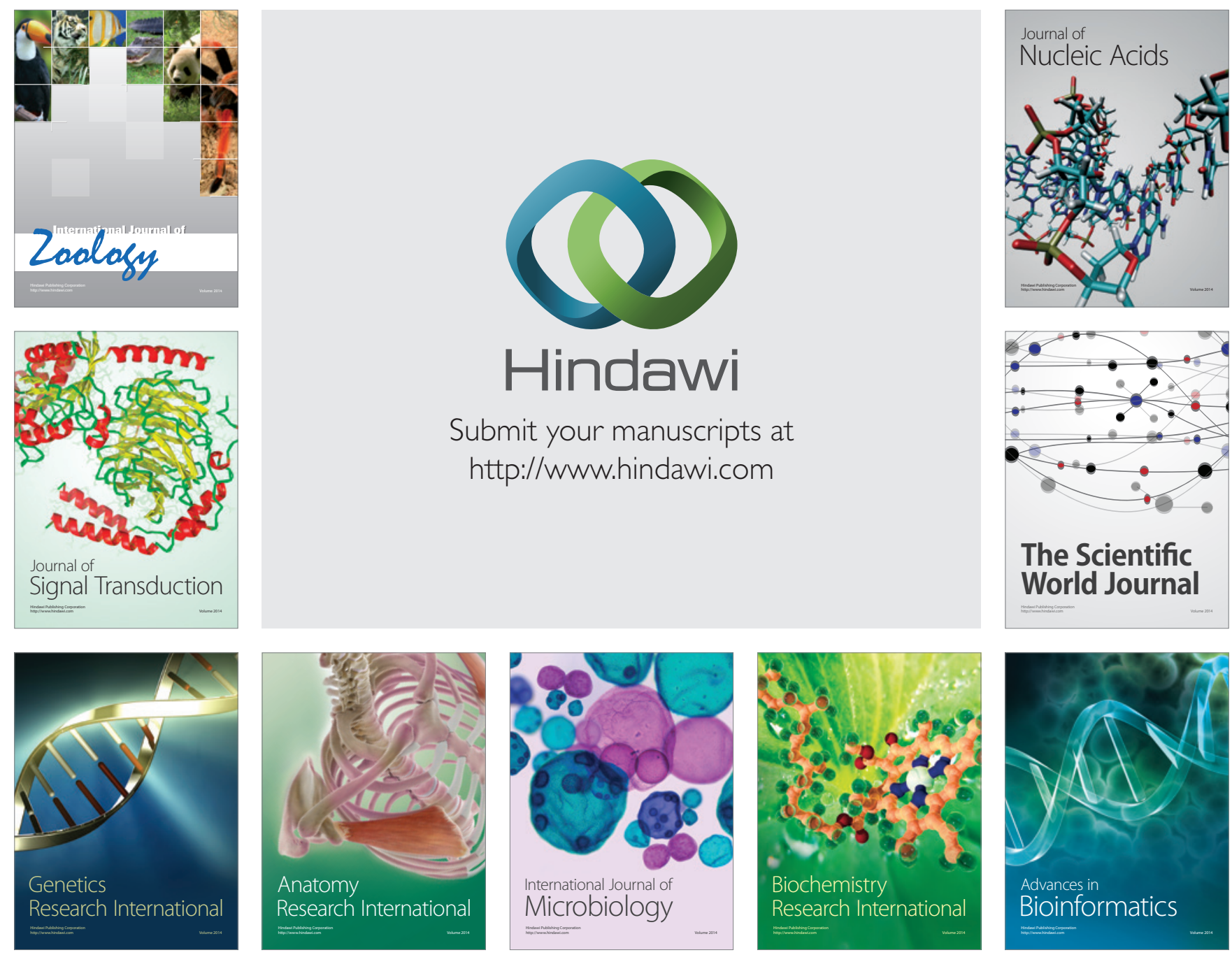

The Scientific World Journal
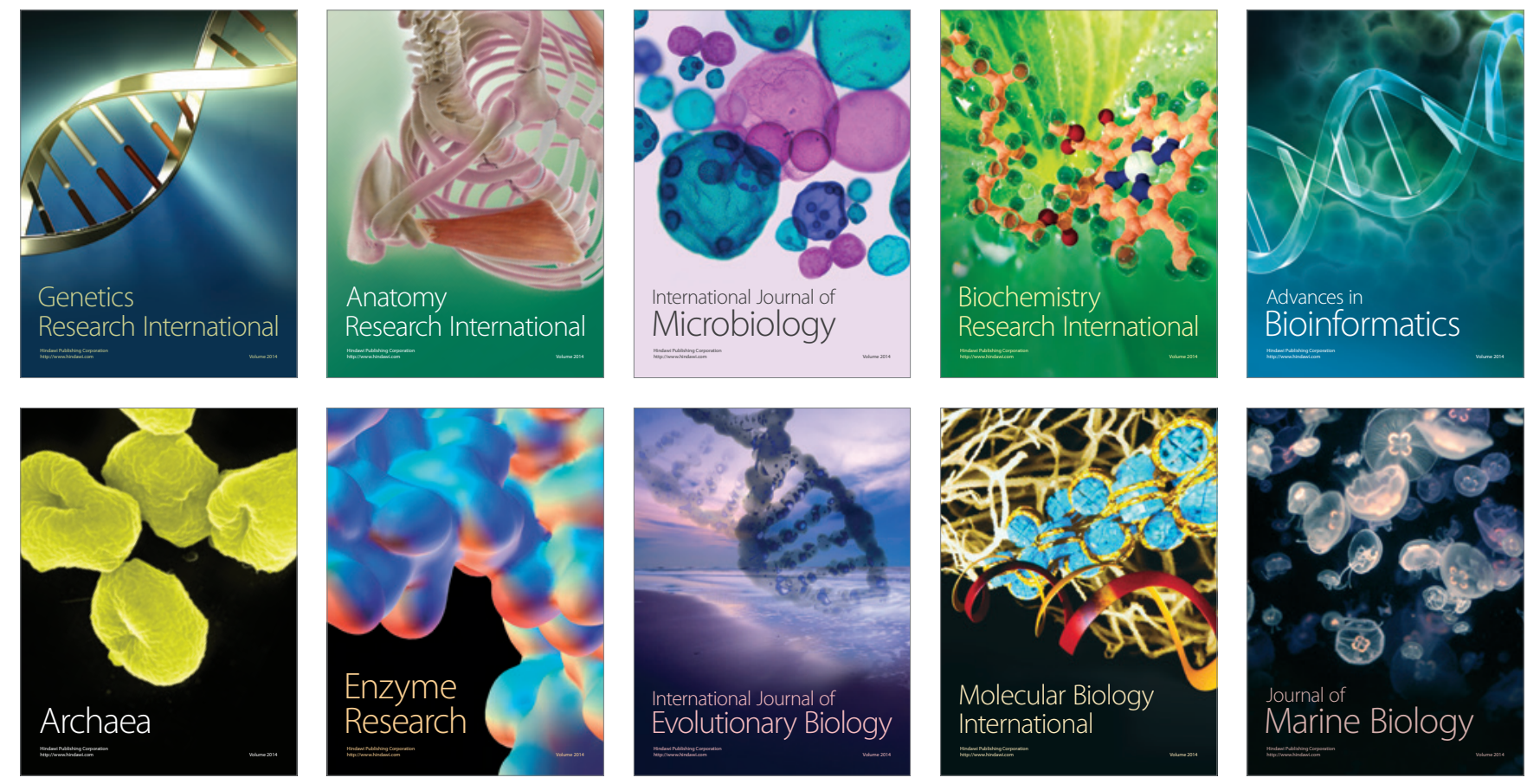